\title{
PENGEMBANGAN DESA WISATA GERABAH DALAM \\ MENINGKATKAN PENDAPATAN MASYARAKAT \\ PUNDONG BANTUL
}

\author{
Iputu Hardani HD, S. ST, M. MPar \\ NIDN. 0506108201 \\ Email: iputu.hardani@gmail.com \\ Dosen Sekolah Tinggi Pariwisata AMPTA Yogyakarta
}

\section{ABSTRACT}

Development the tourism village aims at increasing the society well-being and educating the people in the field of development at the tourism sector, for the purpose is long-term in the next five years on 2021 that Indonesia could bring 10 million foreign tourists with the bases of development of tourist with special interest, one of them is traveled in tourism village.

Pesona Indonesia program is designed by the ministry of tourism and creative economy is a program that is designed to encourage the progress and well-being of local society the for multiefec from the development of tourism itself in a recreational area that enables to expan the labor and the bussinese of fields of tourism .

It means that how can a program capable of blends of internal elements of socio-cultural-dynamic to the development with developing the sectors. In quantity and quality the benefits and its impact of can be looked.

The success of the village when developing its source has a strategic significance for improvements of socioeconomic for people and regions, thus welfare and continuation of tourism village of pottery can work in accordance with the development that is explorative and not exploitive. Especially when we consider in strategic locations tourist village of pottery is located in one the tourism in parangtritis coast very phenomenal.

The form of the final objective as a special target is growing the interest and the awareness for the village community especially around tourist village of pottery in sub-district pundong, to develop this tourist village this to be productive village that able to provide the multiplier efect for increasing of income for the surrounding community by the presence of an increasing the employment opportunities, employment sector is as supporting indicator of and it is for supporting in the development nof creative economy community base on local empowerment.The qualitative method is to determine the way to find, collect, cultivate and analyze and understand the social interaction by means of a deep interview so it will find a clear patterns as approach which is the most effective to accelerate the development that refers to the basis of the basic of rights life for community.

Key word:

\section{PENDAHULUAN}

Paradikma baru, pariwisata menjadi fenomena khusus dimana pariwisata sudah menjadi suatu kebutuhan khusus, hal ini selaras dengna perkembangan dan taraf kualitas hidup masyarakat diperkotaan sehingga para wisatawan nusantara maupun wisatawan mancanegara memiliki kesadaran dan kebutuhan akan sikap berwisata. Sehingga dapat dikatakan bahwa pariwisata adalah milik rakyat, oleh rakyat dan untuk rakyat. Dalam hal ini, rakyat sebagai penggerak sekaligus sebagai pelaku pariwisata, dan hal ini tidak dapat dipungkiri akan eksistensinya dalam mendukung kemajuan suatu obyek wisata disuatu daerah.

Pengembangan desa wisata masih sangat diperlukan dalam rangka meningkatkan pendapatan masyarakat setempat yang berimbas pada kesejahteraan masyarakat setempat melalui pengembangan berbagai aspek atau sektor yang perlu diperhatikan dan harus dibangun oleh pemerintah desa, seperti memperluas pemasaran, bimbingan dan penyuluhan, usaha pendidikan, menciptakan situasi yang menjamin dan mendorong ketenangan berusaha, pendirian lembaga lembaga resmi yang menopang maupun aksesbiliatas menuju ke desa wisata tersebut.

Geografi dan kemasyarakatan Kecamatan Pundong, Kabupaten Bantul batas wilayah:

1. Sebelah Utara : Jalan Parangtritis, dan Kecamatan Jetis

2. Sebelah Timur : Kali Opak, dan Kecamatan Imogiri

3. Sebelah Selatan : Pegunungan Sewu, Kecamatan Kretek, Kecamatan panggang, dan Kecamatan Purwosari

4. Sebelah Barat : Kali Winongo Kecil, Jalan Parangtritis, dan Kecamatan Bambanglipuro

Unsur budaya, perumusan suatu pengem-bangan desa wisata Gerabah di kecamatan Pundong, sebagai kerangka dasar titik tolak dan umpan balik dalam usaha meningkatkan pendapatan masyarakat lokal dengan memperhatikan simpulan-simpulan pemikiran yang berkembang sebagai berikut.

1. Upaya sosisialisasi potensi pariwisata bagi para pelaku wisata di desa wisata Gerabah di Kecamatan Pundong, Bantul sebagai tahap awal untuk 
menyediakan sumber daya manusia seytempat dalam rangka menerima wisatawan.

2. Peningkatan daya dukung masyarakat lokal dan fasilitas pendukung kegiatan wisata perlu dikembangkan dalam rangka meningkatkan pendapatan masyarakat setempat.

3. Sinergitas upaya-upaya pemasaran dan managerial produk wisata dengan keunggulan desa wisata gerabah sebagai penanggulangan kemiskinan perlu ditingkatkan sebagai gerakan bersama antar pemangku kepentingan.

Kajian dari pengembangan desa wisata Gerabah di Kecamatan Pundong ini, bertujuan:

1. Terwujudnya identifikasi kesadaran masyarakat lokal akan potensi wisata dengan konsepsi dan kontribusi masyarakat setempat menjadi sadar akan pentingnya pemahaman terssebut dalam rangka menjaring kunjungan wisatawan, melalui pendekatan :

a. Sosialisasi dan pendampingan Sapta Pesona

b. Memastikan secara khusus kelemahan kelemahan produk desa wisata gerabah di kecamatan Pundong bersumber dari opini masyarakat

c. Peningkatan akselerasi pemberdayaan masyarakat dan daya dukung obyek wisata desa

\section{wisata Gerabah di kecamatan Pundong}

2. Tersusunnya dokumen pemasaran dan managerial dalam rangka pengembangan desa wisata gerabah sebagai wadah peningkatan pendapatan masyarakat lokal, sebagai kerangka dasar implementasi di masa mendatang, melalui pendekatan:

a. Sosialisasi dan pendampingan tentang pemasaran (Product Knowledge) desa wisata Gerabah di kecamatan Pundong, Bantul.

b. Sosialisasi dan pendampingan tentang managerial desa wisata Gerabah di kecamatan Pundong, Bantul dalam rangka meningkatkan pendapatan masyarakat lokal.

Sosialisai dan pendampingan menjadi arah yang gayut dan terarah dalam upaya meningkatkan pendapatan masyarakat lokal sebagai pelaku pariwisata terkait dengan unit analisis, dan menggunakan tahapan :

1. Identifikasi kesadaran masyarakat di desa wisata Gerabah Kecamatan Pundong sebagai upaya meningkatkan pendapatan masyarakat lokal.

2. Analisis daya dukung obyek wisata desa wisata gerabah di kecamatan Pundong, Bantul.

3. Strategi dasar pemasaran dan managerial desa wisata gerabah di kecamatan Pundong dalam meningkatkan pendapatan masyarakat lokal.

Urgensi, Output dan Outcome.

\begin{tabular}{|c|c|}
\hline Subyek & Penjelasan \\
\hline Urgensi & $\begin{array}{l}\text { Pentingnya kajian terhadap pengembangan dan pemberdayaan masyarakat di desa wisata } \\
\text { gerabah kecamatan Pundong, Bantul, berlandaskan pada kebutuhan akan fakta dan ukuran } \\
\text { keberhasilan, pengembangan desa wisata gerabah dengan melibatkan masyarakat lokal } \\
\text { sebagai pelaku pariwisata, sebagai bahan masukan bagi penyempurnaan implementasi } \\
\text { pengembangan desa wisata di masa yang akan datang. Disamping itu fakta dan ukuran } \\
\text { keberhasilan dimaksud dapat menjadi contoh bagi desa wisata yang lainnya dalam skala } \\
\text { lokal maupun nasional. }\end{array}$ \\
\hline $\begin{array}{l}\text { Output dan } \\
\text { Outcome }\end{array}$ & $\begin{array}{l}\text { Output yang diharapkan dari kegiatan kajian ini adalah tersedianya strategi pengembangan } \\
\text { desa wisata yang membahas tentang pemberdayaan masyarakat lokal yang telah } \\
\text { dilaksanakan peneliti sehingga dapat diakses oleh masyarakat, baik masyarakat awam, } \\
\text { praktisi pariwisata maupun masyarakat akademis. Dengan demikian dapat diketahui } \\
\text { kelemahan pengembangan yang telah dilaksanakan dan dapat diambil sebuah kebijakan } \\
\text { yang sesuai dengan kondisi riil di lapangan } \\
\text { Sedangkan outcome yang diharapkan dari kegiatan penelitian ini adalah meningkatkan } \\
\text { pendapatan masyarakat lokal baik kuantitas maupun kualitas sehingga cita-cita pemerintah } \\
\text { dan masyarakat untuk peningkatan kesejahteraan rakyat dapat tercapai. Antara lain: } \\
\text { a. terwujudnya kesadaran penduduk/ masyarakat lokal akan pemahaman Sapta Pesona } \\
\text { b. terbentuknya pengelola desa wisata yang mampu memasarkan dan managerial desa } \\
\text { wisata gerabah } \\
\text { c. terbentuknya pokdarwis. } \\
\text { Program Usulan } \\
\text { a. pelatihan dan bimbingan ketrampilan pemasran dan managerial desa wisata pada } \\
\text { masyarakat } \\
\text { b. pelatihan teknologi berbasis internet serta pendampingan dalam rangka memasaran } \\
\text { desa wisata gerabah di kecamatan Pundong itu sendiri dan memasarkan produk yang } \\
\text { ada didesa wisata gerabah di kecamatan Pundong, Bantul.(memasarkan gerabah via on- } \\
\text { line) }\end{array}$ \\
\hline
\end{tabular}




\section{LITERATURE REVIEW}

Bertolak dari latar belakang, pokok permasalahan penelitian ini adalah Sejauh manakah peranan pengembangan desa wisata Gerabah di kecamatan Pundong Bantul dalam meningkatkan pendapatan masyarakat lokal. Pengetahuan dan pemahaman tentang pengembangan desa wisata gerabah dalam meningkatkan pendapatan masyarakat lokal dari aspek sumber daya manusia dan daya dukung obyek wisata tersebut. Kajian ini memiliki kegunaan bagi pengembangan ilmu pengetahuan, pemasaran dan menegerial tentang desa wisata gerabah, selain tersebut secara minor berperanan sebagai pedoman arah untuk meningkatkan pendapatan mayarakat lokal akan perkembangan desa wisata Gerabah di kecamatan Pundong, Bantul.

Pentingnya Perhatian Pada Sektor Pariwisata

Perhatian terhadap pariwisata sudah sangat meluas tersebar karena sadar akan manfaat-manfaat yang didatangkan bagi negara-negara penerima wisatawan yaitu :

a. bahwa pariwisata menjadi sumber pendapatan valuta asing dengan menjual jasa-jasa dan barangbarang yang berkaitan dengan pariwisata;

b. bahwa pendapatan ini mengalir cepat dan langsung terbagi-bagi secara meluas ke dalam perekonomian nasional, sehingga mampu membagi-bagi laju pendapatan secara meluas, bertambah banyak dan berputar-putar kesegala lapuisan pedagang besar dan pengecer, transportasi, beragam komponen sektor pariwisata, kebutuhan-kebutuhan dan usahausaha yang berdasarkan tingkat pengeluaran konsumen;

c. bahwa pariwisata adalah pasaran lanjutan searah dengan meningkatnya yang begitu pesat tingkat pendapatan keluarga yang tidak habis terpakai, khusunya pada Negara-negara yang industrinya sudah maju;

d. bahwa industri pariwisata jika dibandingkan dengan industri lain, termasuk industri yang investasi modalnya kecil sebanding dengan arus pendapatan yang mungkin;

e. bahwa pariwisata menyediakan suatu pasaran "ekspor" tempat konsumen dating untuk meneliti "produk" tersebut;

f. bahwa produk yang dijual terutama berupa jasa dan tidak dapat dijamah (intangibles), udara yang sejuk, alam yang indah, terdapat tempat-tempat bersejarah, yang kelihatannya secara potensial tidak akan habis-habisnya, dan hanya tunduk pada keterbatasan upaya promosi dan penjualan;

g. bahwa pariwisata adalah sarana yang ampun dan efektif bagi kebijakan umum untuk menciptakan perpaduan sosial dan budaya pada tingkat nasional maupun internasional untuk mengembangkan industri-industri lain dan sarana pemupukan tenggang rasa dan saling pengertian dengan Negara-negara tetanggadfan dunia pada umumnya (Harris, Keer, Foster Ceylon 1988)
Konsep Multiplier

Pariwisata sebagai alat pemicu sektor-sektor yang lain (Multiplier Effect), Salah satu bukti empiris yang disebut Putting the poor fisrt strategic, dengan penerapan di Negara sedang berkembang yaitu di Afrika Selatan menyimpulkan adanya lima strategi penting yang perlu dipertimbangkan dalam upaya pengentasan kemiskinan pada masyarakat pedesaan, yakni : perluasan kesempatan kerja, pengurangan dampak negatif pada lingkungan, pengurangan dampak sosial budaya pariwisata yang negatif, pengembangan kelembagaan. (Janianton Damanik; 2005)

Dampak Pengembangan Kawasan Pariwisata

Dampak pariwisata sebagai suatu aktivitas tidak hanya dilihat dari aspek pembangunan fisiknya saja. Pariwisata, yang komponen pokoknya adalah wisatawan juga mempunyai pengaruh terhadap aspek sosial-ekonomi dari objek wisata yang dikunjungi yaitu terhadap kehidupan penduduk sekitarnya.

Dampak Ekonomi

Dilihat dari kacamata ekonomi makro, jelas pariwisata memberikan dampak positif, karena sebagai suatu industri.. Pariwisata dapat menciptakan kesempatan berusaha, dapat meningkatkan kesempatan kerja ( employment ), dapat meningkatkan pendapatan masyarakat sebagai akibat multiplier effect yang terjadi dari pengeluaran wisatawan yang relatif cukup besar itu, dapat meningkatkan penerimaan pajak pemerintah dan retribusi daerah, dapat meningkatkan pendapatan nasional atau Gross Domestic Bruto (GDB ), dapat mendorong peningkatan investasi dari sektor industri pariwisata dan sektor ekonomi lainnya, dapat memperkuat neraca pembayaran. Selain itu pariwisata juga memberikan dampak negatif antara lain adalah : harga tanah menjadi mahal, pantai - pantai dikaveling, sehingga sering terjadi spekulasi harga yang pada akhirnya meningkatkan harga tanah disekitarnya, di pusat - pusat konsentrasi kegiatan pariwisata harga yang pada akhirnya meningkatkan harga tanah disekitarnya, sumber hayati menjadi susah, yang menyebabkan Indonesia kehilangan daya tariknya untuk jangka panjang, terjadi urbanisasi, pencari kerja mengalir dari desa ke kota - kota besar, ramainya lalu lintas wisatawan, ternyata ditumpangi oleh penyelundupan obat - obat bius dan narkotika. ( Oka, , 2008)

Dampak sosial

1. Densitas wisatawan

Untuk sejumlah peristiwa tertentu sejumlah besar wisatawan berkumpul pada suatu waktu tertentu. Sebagai tambahan, aspek musiman wisatawan berarti bahwa, bagi sebagian besar kawasan tujuan wisata, wisatawan terkonsentrasi pada kawasan tujuan wisata tertentu selama beberapa bulan saja.

2. Efek demonstrasi

Efek demonstrasi adalah istilah yang diberikan untuk usaha penduduk setempat yang mencoba menyamai cara atau tingkah laku tamu - tamu mereka. 


\section{Migrasi}

Secara ekonomi, dalam rangka ikut serta mengambil keuntungan dari kedatangan wisatawan, penduduk setempat di banyak kawasan tujuan wisata yang kurang berkembang meninggalkan tanah mereka dan terjun ke pekerjaan jasa ini.

4. Kebiasaan mengkonsumsi

Bersamaan dengan meningkatnya pariwisata, usahawan lokal mengimpor barang - barang untuk menarik wisatawan. Usahawan lokal mungkin malihat barang - barang impor berkualitas lebih tinggi dibandingkan dengan barang - barang produksi dalam negeri. Sejumlah orang menanamkan keadaan ini sebagai sebuah “ kemajuan”. Tapi kenyataannya, keadaan ini meningkatkan impor , dan karenanya meningkatkan kebocoran dan menghilangkan keuntungan pariwisata.

5. Sikap moral

Sering dikatakan bahwa paariwisata membawa serta pelacuran, kejahatan, perjudian ke sebuah kawasan wisata. Tapi bagaimanapun juga, tidak ada mata rantai yang tampak jelas antara pariwisata dan pelacuran. Meskipun demikian harus diakui bahwa sejumlah kaawasan tujuan wisata menjual empat hal yaitu matahari, pasir, laut, dan seks.

6. Mengukur akibat sosial

a. Euphoria (perasaan bahagia rohani dan jasmani): Pada tingkatan akibat sosial ini penduduk setempat sangat gembira ats perkembangan pariwisata di komunitas tempat mereka tinggal.

b. Sikap acuh tak acuh : Bersamaan dengan tumbuhnya pariwisata, kedatangan wisatawan dianggap sudah memang seharusnya.

c. Merasa terganggu dan jengkel: Pada titik tertentu tumbuhnya pariwisata, menurut penduduk setempat, tidak lagi dapat ditangani segi jumlahnya. Jalan - jalan macet, restoran dan tempat minum penuh sesak dengan pengunjung.

d. Antagonisme ( penentangan): Bila penduduk setempat mulai merasa bahwa masalaah dalam komunitas mereka - polusi, kejahatan, kenaikan pajak - merupakan kesalahan yang ditimbulkan oleh meningkatnya jumlah wisatawan, mereka bisa berubah menentang secara terbuka.

e. Level terakhir : Pada tahapan kelima atau yang terakhir ini mereka - mereka yang berada dalam komunitas setempat lupa bahwa wisatawan tertarik datang ke komunitas mereka pada awalnya karena beberapa alasan fisik maupun budaya. (Robert Christie, 2000)

\section{METODE PENELITIAN}

Metode penelitian yang dipilih peneliti adalah penelitian pada permasalahan yang bersifat sosial dan dinamis. Peneliti memilih menggunakan metode penelitian kualitatif untuk menentukan, mengumpulkan data dengan metode wawancara, mengolah dan menganalisis data untuk memahami interaksi sosial sehingga akan ditemukan pola- pola yang jelas. Lokasi penelitian ditetapkan di desa Jetis kecamatan Pundong, Kabupaten Bantul, Propinsi Daerah Istimewa Yogyakarta. Sample diambil dari 10 warga (informan) sekitar desa wisata di Pundong yang secara langsung menjadi penggerak dan pengembang desa wisata gerabah..

\section{HASIL PENELITIAN DAN PEMBAHASAN}

Pundong merupakan salah satu Desa Wisata yang berada di sebelah timur Kabupaten Bantul. menjadi desa wisata, Pundong sejak bertahun-tahun telah dikenal dengan kerajinan tangan gerabah. Kerajinan Gerabah merupakan aneka bentuk kerajinan yang terbuat dari tanah liat atau lempung. Selain berbelanja dan wisata di Pundong, pengunjung juga bisa melihat proses pembuatan aneka kerajinan tangan gerabah. Kerajinan tangan gerabah dibuat dalam berbagai bentuk produk, seperti alat rumah tangga, hiasan rumah, suvenir, vas, guci, benda-benda antik dan sebagainya.Pundong merupakan kawasan sentra produksi kerajinan gerabah. Sebagian besar penduduk Pundong bermata pencaharian sebagai perajin gerabah.

Gerabah di Desa Pundong sebagai hasil kerajinan tradisional dilakukan secara individu maupun kelompok produksi dengan peralatan dan sistem pembentukan sangat sederhana, serta tungku pembakaran yang dibuat sederhana. Fungsi estetik muncul setelah gerabah dapat dijadikan sarana oleh pengrajin untuk menuangkan idenya dengan memadukan unsur bentuk, bidang, tekstur serta warna yang natural (kualitatif) yang memiliki potensi untuk dikembangkan secara berkesinambungan sehingga dapat memenuhi kebutuhan wisatawan yang berkunjung ke desa wisata pundong.

Usaha indusatri gerabah di Desa Pundong sangat mungkin berkembang terutama ketika modal, sumber daya manusia, teknologi, bahan baku, organisasi pengrajin, kebijakan pemerintah, strategi pemberdayaan masyarakat berupa perencanaan program misalnya (i) pembentukan paguyuban pelestari industri gerabah, (2) pelatihan kewirausahaan dan ketrampilan pembuatan gerabah yang inovatif/ design modern, (3) pengembangan permodalan dan (4) pengadaan alat pengeringan dan (5) pelatihan pemasaran termasuk e-selling yang sederhana.

\section{KESIMPULAN}

Berdasarkan hasil penelitian, pengamatan dan pembahasan yang telah dilakukan penulis, maka dapat disimpulkan bahwa pengem-bangan desa wisata yang telah dilakukan belum berjalan baik. Antara lain fasilitas yang belum mewadai dan stakeholder yang terkait belum bersinergi dalam mengembangkan desa wisata tersebut. Daya tarik utama utama yang berkembang tidak diimbangi dengan konsistensi dari para pelaku 
pengrajin gerabah di daerah tersebut. Adapun saran yang yang dapat disampaikan penulis agar pendapatan masyarakat setempat dapat meningkat:

a. Para pelaku wisata diberikan latihan secara berkelanjutan terutama diversifikasi produk gerabah dengna model yang beragam

b. Pelatihan pemasaran, sehingga tidak hanya mengandalkan penjualan dari kasongan saja

c. Aksesbilitas menuju lokasi agar diperlebar sehingga bus besar bisa masuk

d. Optimalkan peran serta dari para pelaku wisata, pihak pemerintah dan pihak swasta agar pendapatan masyarakat setempat dapat meningkat

e. Segmen pasar dikelola secara jelas dan menyebar.

\section{DAFTAR PUSTAKA}

BPS Bantul,2010. Kabupaten Bantul dalam angka, Kabupaten Bantul, Yogyakarta

BPS DIY, 2008. Tingkat Kemiskinan di Provinsi DIY pada Maret tahun 2008, Berita Resmi Statistik, Yogyakarta
BKK Propinsi .DIY,2006, Strategi Penanggulangan Kemiskinan Daerah , Yogyakarta

Dinas Pertanian Kab. Bantul, 2007. Studi Ketahanan Pangan Kabupaten Bantul, Bantul, Yogyakarta

Dinas Tenaga Kerja dan Transmigrasi Provinsi DIY. 2007. Proyeksi Kependudukan Provinsi DIY, Yogyakarta

Ravallion, Martin, 1992. Poverty Lines in Theory and Practice : Living Standards Measurement Study, World Bank : Working Paper No. 13

Winardi, 1989. Strategi Pemasaran, Lembaga Penerbitan Fakultas Ekonomi UGM, Yogyakarta

Harris, Keer, Foster Ceylon tourism Plan : Salah Wahab ; Manajemen Kepariwisataan

Janianton Damanik. 2005. Penanggulangan kemiskinan melalui Pariwisata. Dari Konsep Menuju Implementasi: Pusat Studi Pariwisata UGM Yogyakarta. 